\title{
Comparative Research on Cooperative Mechanisms for Cross-Regional Emergency Management between China and America
}

\author{
Mufu Cai ${ }^{1}$, Sulin Pang ${ }^{2}$ \\ ${ }^{1}$ School of Public Administration and Emergency Management, Institute of Finance Engineering, Jinan University, Guangzhou, \\ China \\ ${ }^{2}$ Guangdong Emergency Technology Research Center of Risk Evaluation and Prewarning on Public Network Security, \\ Guangzhou, China \\ Email:505456412@qq.com
}

How to cite this paper: Cai, M.F. and Pang, S.L. (2017) Comparative Research on Cooperative Mechanisms for Cross-Regional Emergency Management between China and America. Open Journal of Social Sciences, $\mathbf{5}$, 59-72.

https://doi.org/10.4236/jss.2017.53007

Received: January 23, 2017

Accepted: March 13, 2017

Published: March 16, 2017

Copyright () 2017 by authors and Scientific Research Publishing Inc. This work is licensed under the Creative Commons Attribution International License (CC BY 4.0).

http://creativecommons.org/licenses/by/4.0/

\begin{abstract}
In recent years, the emergency in cross regions has high-frequent occurrence, and the higher requirements for wholly overall planning and disposal of emergencies have been proposed to Chinese departments for emergency management. The paper summarizes and analyzes advanced experience of cooperative mechanism for cross-regional emergency management in America via comparison on cooperative mechanisms for cross-regional emergency management between China and America, so as to provide helpful experience to improve Chinese cooperative mechanism for cross-regional emergency management.
\end{abstract}

\section{Keywords}

Emergency Management, Cross Region, Cooperative Mechanism

\section{Introduction}

For the past few years, cross-regional public emergencies, such as SARS Infectious Disease Event in 2002, Extreme Sewage Event of the Songhua River in 2005 and Snow and Ice Disaster of the South in 2008, etc. have high-frequent occurrence. Cross-regional public emergencies are characterized by wide influence, great damage and big difficulty in handling, etc., and it is difficult for a single regional department to effectively handle these events. Simultaneously, the Third Plenary Session of the Eighteenth Party Congress has clearly put forward the requirement of "establishment and improvement of coordination mechanism for cross-regional city development"; therefore, the establishment and improvement of cooperative mode of cross-regional emergency management have become the 
existing topic to be necessarily researched.

America is one of the countries with the highest level of emergency management in today's world, and has developed a series of mature emergency cooperation on cross-regional public emergencies. The paper summarizes and analyzes advanced experience of cooperative mechanism for cross-regional emergency management in America via comparison on cooperative mechanisms for crossregional emergency management between China and America, so as to provide helpful experience to improve Chinese cooperative mechanism for cross-regional emergency management.

The outline of this paper are as follows: first, the paper has classified and oriented the theoretical basis of cross-regional public emergency; second, the paper has compared and summarized the different cooperative mechanisms for cross-regional emergency management between China and America; third, the paper introduces the relevant experience from American cooperative mechanism for cross-regional emergency management to China; fourth, suggestive conclusion has been given.

\section{Theoretical Basis}

\subsection{Definition of Cross-Regional Public Emergencies}

Cross-regional public emergency refers to public emergencies and those disasters endangering life and property security of the public, social order and public security and beyond out of local scope of governmental jurisdiction in relative terms of administrative divisions at different levels [1].

\subsection{Characteristics of Cross-Regional Public Emergencies}

1) Higher complexity. Different from emergencies in single region, cross-regional public emergencies are more complex, reflected in characteristics of wide influence, greater damage and higher derivation. The first is the wide influence. One the one hand, the division of administrative region is the subjective behavior of human beings, while the public emergencies are objectively not restricted by it, and the occurrence and development of natural disasters including typhoon, earthquake and sand storm, etc. will not be stopped for division of administrative region. Therefore, in case of large natural disasters, many administrative regions may be frequently involved; for example, Snow and Ice Disaster of the South in 2008 struck nineteen provinces and cities in South China. On the other hand, the advanced science and technology and frequent population mobility in recent years have enlarged the spreading range of public emergencies; for example, the sharp emergence of self-media provides the platform for spreading Internet rumors and the population with high mobility may trigger more public health problems. The second is the greater damage. Because of relatively wide damage area and high number of victims of cross-regional emergencies, the damage is greater. For example, Super Typhoon Saomai in 2006 struck Taiwan, Zhejiang, Fujian and other regions of China, which caused financial loss (USD 2.5 billion) and death of thousands of people. The third is the higher deri- 
vation. Because of coupling, derivation and other characteristics of emergencies, the cross-regional public emergencies are easier to result in other kinds of emergencies with enlargement of damage area and extension of disaster time, such as landslide, burning house and epidemic disease, etc. frequently caused after great earthquake.

2) High difficulty in disposal. With characteristics of wide influence and great damage, etc. of cross-regional public emergencies, the disposal of such event has the higher difficulty. The first is the unclear jurisdiction. Chinese emergency management system stipulates the liability system for emergency management mainly dominated by attribution. When occurring emergencies, the local government is the first organization responsible for solving the event. However, in case of cross-regional emergencies, several administrative regions are involved, and the local government may only have right of disposal for emergencies within own regional management scope of jurisdictions. Therefore, there is dispute on cross-regional emergencies. The second is the insufficient information. Under a situation of public emergencies, the information resource is of great importance to government guidance of social public feelings and disposal of public crisis. However, after the occurrence of cross-regional emergencies, the weak leadership of a central government and unreasonable division of labor, etc. are caused objectively for Chinese existing administrative system. Details are reflected in imperfect and uniform information department, information withholding of local government where an emergency occurs and transmission lag of information on emergencies between local governments with same level, etc. In the Pollution Event of the Songhua River in 2005, for no effective information sharing of Harbin Government, the panic of social mass was caused, and simultaneously, other affected provincial governments disposed pollution event with lag due to it. The third is the lack of resource. A large number of emergency resources are required for supporting the disposal of public emergencies of cross regions, especially cross province and cross border, and the emergency resource reserve of single administrative region is limited for solution of large emergencies. With an example taken of the disaster-hit area of Mianyang of 2008 Wenchuan Earthquake, 600 thousand tents were required in this area for settlement of quake-affected residents at that time. However, at that time, the local emergency resource materials storehouse only had about 200 tents, and consequences would be disastrous without supporting of emergency resources of the central government and other provinces.

\subsection{Definition and Necessity of Cross-Regional Emergency Management Mechanism}

Cross-regional emergency management refers to effective integration of emergency resource fragments in each area and a series of measures taken to prevent, control and dispose cross-regional emergencies in scope of influence [2]. Moreover, the cross-regional emergency management refers to emergency management organization form set for reduction of emergencies and damage to public 
security risk jointly confronted among adjacent areas and between the upstream and downstream of drainage basin to the greatest extent via breakthrough of regional segmentation and joint solution of emergencies [3].

The establishment of cooperative mechanism for cross-regional emergency management is the existing effective response mode to cross-regional public emergencies. Such cooperative mode may make mutual coordination and cooperation among all regions and departments, which possibly realizes both uniform centralized dispatching of resources and information sharing of emergencies so as to resolve weak leadership of central government and contradiction of mutual prevarication and improve efficiency of emergency management.

\section{Comparative Research on Cooperative Mechanisms for Cross-Regional Emergency Management between China and America}

The paper mainly make a comparison on cooperative mechanisms for cross-regional emergency management between China and America from six aspects of institutional arrangement, management organization, operating process, information communication, resource allocation and rescue team.

\subsection{Comparison on Institutional Arrangement}

1) America: Emergency Management Assistance Compact. In America, Emergency Management Assistance Compact (hereinafter referred to as EMAC) is the legal compact of American cross-regional emergency management mechanisms. EMAC allows sharing information in case of all kinds of disasters, and determines the objectives, duties and responsibilities of cooperation content among all cooperative parties for American cross-state emergency management. It provides the legitimacy of American cross-state emergency management cooperation; establishes the basic system framework of regional emergency management cooperation for all states; boosts movement of cross-state regional emergency management cooperation towards institutionalization, sequencing and integration, and effectively develops the capacity of implementation of cross-state emergency management cooperation.

2) China: no corresponding institutional norm. In China, Law on Response to Emergencies of the People's Republic of China is the legal framework of Chinese emergency management. Article 7 of Chapter I in Law on Response to Emergencies 4 indicates that "the liabilities for response to emergencies in administrative regions shall be undertaken by county-level people's government, where two or more administrative regions are involved, by the upper people's government to which relevant administrative regions jointly belong or jointly undertaken by the upper people's governments of relevant administrative regions [4]". This provision provides the institutional basis to cooperative mechanism for cross-regional emergency management, but has no corresponding institutional norm on rights and liabilities distribution, disposal process and funds and materials, etc. in cross-regional emergency management cooperation. 


\subsection{Comparison on Management Organization}

1) America: National Emergency Management Association. American cross-regional emergency cooperation is managed by National Emergency Management Association (NEMA), and the specific operation is undertaken by the EMAC Committee of NEMA consisting of state representatives of its member [5]. NEMA commits itself to improving emergency preparedness and response and recovery capacities in all emergencies, disasters and threats of the country, and exchanging information on topic of emergency management mutually concerned so as to promote the public security. State Government Council will actively support NEMA to realize objectives of information supply and network supporting to directors of emergency management bureau of the state government and participation in other national and regional organization dialogue on emergency management affairs. NEMA has established good cooperative relationship with United States Department of Homeland Security and Federal Emergency Management Agency. With interstate information exchange, the national emergency management system is established and strengthened, and interstate collaborative partners for response to public security challenges of all states are assisted [6].

2) China: Joint Conference System. In China, for no available specific legal system to standardize cooperative mechanism for cross-regional emergency management, China has no uniform cooperative management organization for emergency management yet. At most of time, Chinese cooperative organization for emergency management mainly cooperates with inter-regional government organization with same level to establish Joint Conference System, jointly make research and decision on cooperation items and put it into practice. For example, three provinces of Beijing, Hebei and Tianjin have established Beijing-Tianjin-Hebei Emergency Cooperation Mechanism which is jointly managed by Beijing Emergency Office, Tianjin Emergency Office and Hebei Emergency Office. Such mechanism strengthens cooperation and coordination and improves practical ability of emergency disposal via organization of joint cross-regional emergency exercise, and convokes a joint conference per year to analyze, research and judge public security situation of three places and make a research and decision on emergency cooperation items. It also makes long-term communication in the aspect of normal establishment of emergency information, emergency platform interflow and emergency security ability, etc. to actively promote establishment of emergency cooperation mechanisms of basiclevel government and relevant department in three places. Joint Conference System effectively promotes the communication and development of cross-regional emergency management cooperation, but still has many problems existing in the aspects of rights and liabilities distribution and unified command. However, the office set under Joint Conference System mostly exercises the function of connection and communication, and is equal to the forum or arrangement department for joint conference. It has no compulsory decision-making and execution functions for loose setting and difficulty in formation of public authority. When 
occurrence of large emergency, with many provinces involved, the main responsible body for cross-regional emergency management cooperation is difficultly determined. Simultaneously, Joint Conference System consists of emergency offices of each region, and for different situations of each region and consideration on benefit in the region personally responsible, each emergency office might have individual preference in links of resource allocation, assistance and reestablishment, etc., so that the command and decision from the overall situation may not easily be formed. Cooperation among government organizations is reflected by Joint Conference System in most cases.

\subsection{Comparative Research on Operating Process}

1) America: PARDR model. The operating process of American cross-regional emergency management cooperation of emergencies takes PPRDR model as the framework. PARDR regards help-seeking state and aid state as objects, including five phases of preparation, activation, request, deployment and reimbursement. PARDR model is the cooperation process of emergency management under functional orientation and collaborative implementation among governments, and the operating process is shown as Figure 1. In preparation phase, it is necessary for members in EMAC to participate in formulation of the plan of emergency management cooperation, training and exercise of the plan of emergency management cooperation, and EMAC has stipulated responsibilities of members for emergencies and operating process, and shared emergency management resources among members, etc. In activation phase, if the emergency of stricken state is beyond of emergency disposal capacity of such state, the governor of this state may announce the entry of emergency state, and inform EMAC Committee through information network in operation system of EMAC. In request phase, the stricken state may make a request on resource aid to other states

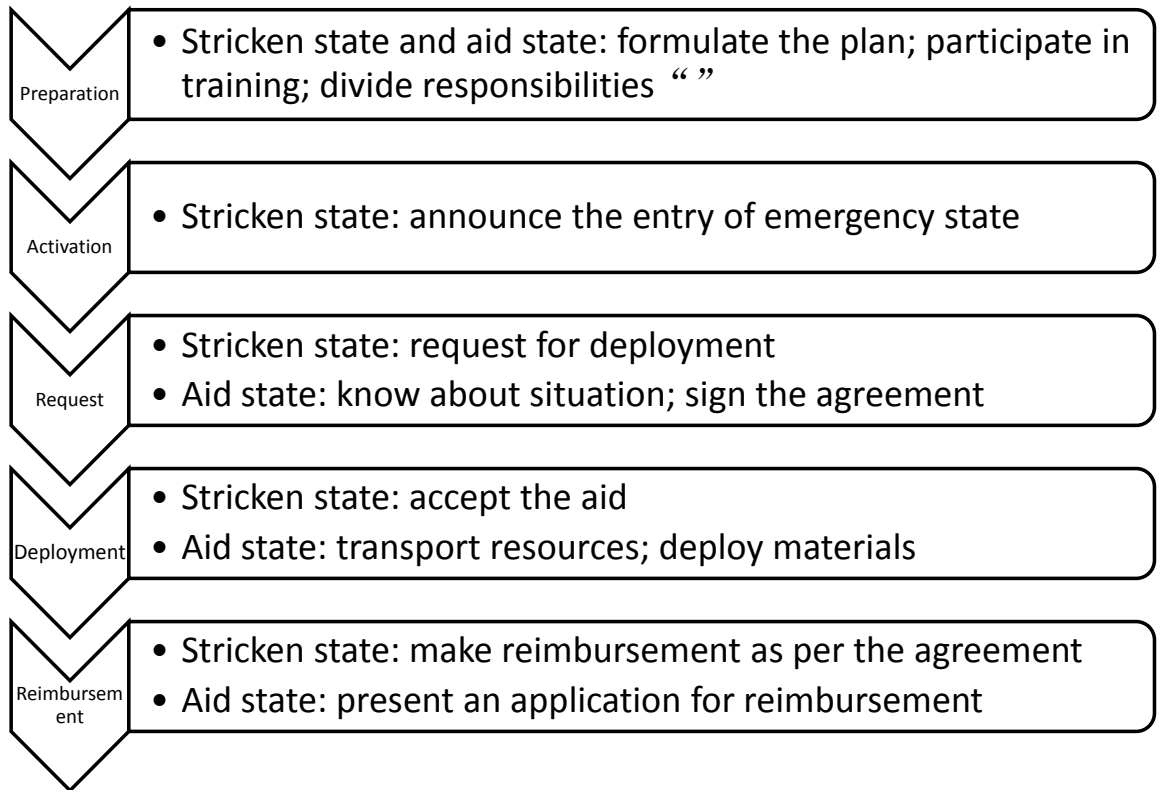

Figure 1. PARDR model. 
when he has confirmed that emergency resources in state have been used up, because EMAC stipulates the basic process of request for interstate emergency management aid and main respective responsibilities of help-seeking state and aid state. In deployment phase, after the occurrence of disaster event, the government of aid state decides the type and size of allocation resources based on scale, scope, damage level and emergency management capacity of the stricken state. When the stricken state and aid state have concluded the cooperation agreement of interstate emergency management, the aid state will deploy and transport emergency resources to the stricken state. In reimbursement phase, following the completion of emergency aid task, the aid state may present an application for reimbursement to the stricken state. Scope of reimbursement is generally in the cooperation agreement of emergency management signed, while emergency management organizations and professional representatives of member states are responsible for aid and reimbursement. PARDR model provides the flexibility and initiative of emergency management cooperation to members in EMAC, and generates the positive interactive cooperation relationship between states; simultaneously, it improves the cooperation level and efficiency of cross-regional emergency management.

2) China: scattering-cooperation mode, leading-participation mode and assistance-cooperation mode. Chinese scholars have summarized the existing cooperative mechanism for cross-regional emergency management of China into three modes, including scattering-cooperation mode, leading-participation mode and assistance-cooperation mode [7]. Scattering-cooperation mode mainly means that member organizations of all regions dispatch relevant personnel to form emergency inspection team to a periodically check possible crisis and hidden trouble in regions when necessary. Such team is the temporary organization based on task rather than a permanent organization. Leading-participation mode is mainly reflected in a situation where the area with the largest influence from crisis is taken as the leading area, and adjacent areas affected or to be affected participate in response to public crisis so as to improve efficiency of emergency management. "Assistance-cooperation mode has main characteristic, where the cross-regional cooperation is firstly dominated by initiative aid of place without crisis in the crisis management and the pairing-assistance and counterpart-assistance are carried out with uniform arrangement of the central government, and the relationship between aiding organization and aided organization is translated into counterpart-economy cooperation based on industrial support with normalization of production and living of disaster area [8]". It can be seen that the cooperation mode of scattering-cooperation mode needs to dispatch relevant personnel to form inspection team when necessary, and it is applicable in early warning phase prior to crisis outburst. When crisis outburst, the applicable leading-participation will become initiative cooperation type to actively respond to the crisis, while the assistance-cooperation mode applies to the restoration and reconstruction phase. Therefore, among local governments, possibly select different cooperation mode based on demands for crisis manage- 
ment. From the above cooperation modes, it can be seen that the leading cooperation mode on emergency management in China is mostly temporary cooperation type. Such mode has disadvantages, including no permanent uniform command organization and no advanced risk assessment among cooperation partners, lack of advanced cooperation plan, lack of cooperation experience among rescue teams and no investigation of emergency resource, etc., when disposal of large emergency.

\subsection{Comparison on Information Communication}

1) America: sharing of information on disaster situation. In America, the cooperation of cross-regional emergency management especially attaches importance to sharing of information on disaster situation. In the aspect of legislative guarantee, Freedom of Information Act (hereinafter referred to as FOIA) is the administrative laws and regulations on information openness of Federal Government of America, such as the national rescue and preparation plan and security electronization network plan carried under the cooperation on emergency response alliance between U.S Department of Transportation and COMCARE. OASIS has issued 2 interdisciplinary standards of emergency information, including: general early warning agreement and emergency data exchange language. In the aspect of information sharing technology, American emergency linkage mechanism is a kind of system type where all resources of the government are integrated, and the special emergency linkage center with the unique special warning service No. has been established (such department makes front command and emergency rescue with full powers on behalf of the government or assists the specialized organization linked to the plan for crisis management of comprehensive linkage based on disposal demands for event type) [9].

2) China: emergency information notification system. In China, among members of emergency cooperation mechanism, the information notification system has been generally established, and it might include that emergencies and early-warning information of adjacent areas shall be timely notified to relevant area, and the emergency preparedness will be reminded for joint prevention and solution. Some cooperative mechanisms for cross-provincial emergency management take advantages of governmental emergency platform of Internet communication to strengthen information communication and emergency discussion, which has successfully prevented and disposed several emergencies. However, in the area lack of emergency cooperation mechanism, there are still phenomena existing of incapability of sharing disaster information, emergency information lag and low information transmission efficiency, etc., and the main reason is no establishment of emergency management information platform with wide coverage and strong practicability.

\subsection{Comparison on Cooperation Resource Allocation}

1) America: resource deployment via the agreement. In America, many emergency resources are privately owned. Therefore, the government necessarily enters into the agreement with the owner of these resources to ensure resource 
guarantee when response to emergencies. Through signature of the agreement for emergency resources, when response to emergencies, a region may provide resources, facilities, services and other supports necessary for emergency disposal for other areas. With the mutual aid agreement, the emergency resource management is more effective and efficient, which ensures the standardization of resource guarantee process and improves the operability.

2) China: lack of scientific management method. The integration manner of Chinese cross-regional emergency resources is lack of scientific management method. A temporary management committee may be established by relevant departments only when occurrence of a sudden event, and then the funds are urgently allocated. If worse comes to worst, no effort might be spared for sudden preparation. Under highly fragmented and segmentary emergency management system, various material resources reserved are managed and used by departments with different functions, and disadvantages reflected include that: on the one hand, the resource allocation among departments is repeated for driving and expansion of department benefits, which seriously affects allocation efficiency of social material resources and easily causes a large number of idle and wasted resources; on the other hand, the emergency mode of sub-department reservation and use of resources will easily have a situation where the resource of a department is idle, while that of the other department is deficient, and the social emergency response could not play the function of linkage and collaboration [10].

\subsection{Comparison on Rescue Team}

1) America: cross-regional multi-party cooperation. American cooperative team for cross-regional emergency management consists of professional rescue teams of each state, and those part-time personnel and volunteers will assist the implementation of work of rescue team. In the emergency rescue team, professional teams of firefighters, policemen and personnel for medical aid, etc. are the backbone force of the emergency management team, and personnel participating in rescue must be strictly trained, take appointment with certificates, and jointly complete rescue operation with interaction and coordination.

2) China: insufficient reserve of talents. In China, the reserve of talents in the cooperation field of cross-regional emergency management is lack, which mainly reflected in the following aspects, including that the first is relatively insufficient gross of talents for professional emergency response and no sufficient mobilization of social resources; the second is unreasonable structure of emergency personnel and simple skills as well as no capability of adaptation to demands of emergency management for interdisciplinary talents; the third is the general lack of corresponding education on crisis management of Chinese institutions of the higher learning and the great shortage of research-based talents for emergency management (the training on personnel for emergency response remains to be further strengthened); the fourth is the single application-oriented or technology-based talents of emergency manpower resources and relatively few interdisciplinary talents with strong comprehensive ability; the fifth is mere formality of 
most of establishment of personnel setting system and no development of its proper functions. In the view of Chinese existing situation, the central and local governments have not formed the long-term mechanism of expert database establishment and operation yet. The government will organize relevant experts to participate in emergency work only in a special event. However, once the completion of work, the expert team will be immediately dismissed, and when it is necessary for the next time, it will be reorganized. Thus, it can be seen that the government applies expert database mainly during response to crisis event, and is lack of importance to aspects of early warning, restoration, reconstruction and assessment after disaster, etc. of emergencies.

\subsection{Conclusion on Cooperative Mechanisms for Cross-Regional Emergency Management of Two Countries}

With the comparative research, it can be found that American existing cooperative mechanism for cross-regional emergency management has been relatively perfect. PARDR model makes the cross-regional cooperation process more specific, clear and flexible, and American cross-regional emergency management activity efficient and uniform, while for Chinese emergency management mechanism is still in the start-up stage and other cross-regional emergency management mechanism has the lower efficiency and could not be uniformly mobilized, the system still remains to be improved. We could see the difference in Table 1.

\section{Reference Experience from American Cooperative Mechanism for Cross-Regional Emergency Management to China}

Chinese cooperative mechanism for cross-regional emergency management is

Table 1. Conclusion on cooperative mechanisms for cross-regional emergency management of two countries.

\begin{tabular}{|c|c|c|c|c|}
\hline \multicolumn{5}{|c|}{ Comparative Research on Cooperative Mechanisms for Cross-regional Emergency Management between China and America } \\
\hline Items & America & Characteristics & China & Characteristics \\
\hline $\begin{array}{l}\text { Institutional } \\
\text { arrangement }\end{array}$ & $\begin{array}{c}\text { Emergency } \\
\text { Management } \\
\text { Assistance Compact }\end{array}$ & $\begin{array}{l}\text { Institutionalization } \\
\text { and sequencing }\end{array}$ & $\begin{array}{c}\text { No corresponding institutional } \\
\text { norms }\end{array}$ & Lack of legal framework of cooperation \\
\hline $\begin{array}{l}\text { Management } \\
\text { organization }\end{array}$ & $\begin{array}{l}\text { National Emergency } \\
\text { Management } \\
\text { Association }\end{array}$ & Unified management & Joint Congress System & Lack of authority \\
\hline Operating process & PARDR model & $\begin{array}{l}\text { Specific, clear and } \\
\text { flexible cooperation } \\
\text { process }\end{array}$ & $\begin{array}{l}\text { Scattering-cooperation mode, } \\
\text { leading-participation mode and } \\
\text { assistance-cooperation mode }\end{array}$ & $\begin{array}{l}\text { No permanent uniform command } \\
\text { organization }\end{array}$ \\
\hline $\begin{array}{l}\text { Information } \\
\text { communication }\end{array}$ & $\begin{array}{l}\text { Sharing of information } \\
\text { on disaster situation }\end{array}$ & Efficiency; uniformity & $\begin{array}{l}\text { Emergency information } \\
\text { notification system }\end{array}$ & $\begin{array}{l}\text { Incapability of sharing disaster information, } \\
\text { emergency information lag and low } \\
\text { information transmission efficiency }\end{array}$ \\
\hline $\begin{array}{l}\text { Resource } \\
\text { allocation }\end{array}$ & $\begin{array}{l}\text { Resource deployment } \\
\text { via the agreement }\end{array}$ & $\begin{array}{l}\text { Standardization; } \\
\text { operability }\end{array}$ & $\begin{array}{l}\text { Lack of scientific management } \\
\text { method }\end{array}$ & $\begin{array}{l}\text { Highly fragmented and segmentary; } \\
\text { resources scattered }\end{array}$ \\
\hline Rescue team & $\begin{array}{l}\text { Multi-party } \\
\text { cooperation }\end{array}$ & $\begin{array}{l}\text { Universal emergency } \\
\text { response }\end{array}$ & Insufficient reserve of talents & Incapability of uniform mobilization \\
\hline
\end{tabular}


the important emergency management mechanism for large emergencies increasingly occurring in cross regions, and has remarkable effect in the aspect of large emergencies. According to the statistics, up to the end of 2013, China has established nearly 1200 cooperative mechanisms for cross-regional emergency management with different levels and types, and these projects of GuangdongHongkong-Macau Cooperative Mechanism for Emergency Management, PanPearl-Delta Regional Cooperative Mechanism for Emergency Management and Beijing-Tianjin-Hebei Cooperative Mechanism for Emergency Management, etc. have obtained good effect in the aspect of emergency management cooperation under region expansion. However, as a kind of innovative mechanism, with reasons of inadequate experience and lack of practice, etc., Chinese cooperative mechanism for cross-regional emergency management stills needs to be improved. The reference to advanced experience of American cooperative mechanism for cross-regional emergency management may make up the insufficiency of Chinese cooperative mechanism for cross-regional emergency management and improve the level of emergency management. Specific reference measures are as follows:

\subsection{Strengthening of Legal Construction}

When amendment of laws and regulations on emergency management, necessarily strengthen contents on cross-regional emergency management, and when formulation of governmental emergency plan, necessarily incorporate adjacent areas into the scope of consideration of emergency plan. Cooperative mechanism shall formulate the emergency plan and prepare the planning for public security risk, quicken the formulation and amendment of relevant plans, materialize and refine specific measures, regard them as the binding institutional documents for cross-regional emergency management cooperation, and ensure that all cooperative parties will timely and jointly make a solution when occurrence of cross-regional emergencies.

\subsection{Enhancement of Mechanism Publicity}

Cooperative mechanism for cross-regional emergency management has obtained remarkable effect in the practice of emergency management. However, Chinese cooperative mechanisms for cross-regional emergency management still have not been popularized, and most of them are limited to cross-provincial emergency cooperation, and the cross-regional cooperation among prefectures and specific regions is less. Therefore, emergency management organizations of governments with different levels and relevant departments regard the establishment of cooperative mechanism for cross-regional emergency management as an important content for strengthening of emergency management. Timely organize, exchange and popularize good experience and practice of all regions, and drive the cooperation of cross-regional emergency management. When each region establishes and improves the cross-regional development coordination mechanism, incorporate emergency management cooperation into the general 
cooperation framework for overall planning and consideration, and guide regions to strengthen regional cooperation to continuously promote regional level of emergency management cooperation.

\subsection{Optimization of Resource Allocation}

Chinese existing emergency management resources are still in highly fragmented and segmentary state with resources scattered, and among cooperative members for emergency management, the efficient sharing of resources could not be realized; the effective supply of manpower, material resources, financial resources and other public security resources may not be guaranteed, and the integral joint response force cannot be formed. Therefore, members in cooperative mechanism for emergency management shall improve the reserve system of emergency relief materials based on sufficient investigation, and gradually enlarge storage volume of emergency materials, boost establishment of emergency materials management, and improve the transportation efficiency of emergency materials in accordance with practical situation.

\subsection{Construction of Information Platform}

A key of disposal of large cross-regional emergency is to guarantee the transparency, timeliness and accuracy of disaster information in regional disposal subjects. Therefore, relevant organizations for cross-regional emergency management shall construct information sharing platform of cross-regional emergency management, and build an information creation mechanism with wide coverage, fast transmission speed and high information trueness to ensure that the information in stricken region will be accurately reported to members in cooperative region at the first time and provide science and technology support for emergency management cooperation.

\subsection{Establishment of Talent Team}

For the disadvantage of Chinese highly fragmented and segmentary system, the emergency manpower resource in all administrative regions of China is still lack of the operation mechanism with efficient running and good cooperation. Therefore, among cooperative regions for emergency management, necessarily establish the cooperation team of talents for emergency management; know about and register emergency management resources in regions, and promote the function of manpower resource in cross-regional emergency management cooperation by means of training, development and depending on teaching resources in colleges and universities, etc., to cultivate the emergency team with modern emergency management quality and professional skills.

\subsection{Universal Emergency Awareness}

Objectives of cross-regional emergency management cooperation include integration of emergency management resources in cross regions and improvement of emergency management level. To further enlarge emergency management 
cooperation, it is necessary to set up universal emergency awareness in full scope to make all circles in society participate in emergency management cooperation. On the one hand, emergency management does not belong to work of governmental organizations or professional teams for emergency, and those non-profit organizations, volunteers and common citizens shall participate in emergency management. Universal participation in emergency management cooperation may both enhance people's emergency and disaster prevention skills and simultaneously build a favorable atmosphere of emergency culture within scope of the whole society. On the other hand, take safety knowledge on emergencies as main contents; propagandize emergency skills of public health, natural disaster, production accident and social security, etc. in school, community, rural area and the scope of the whole society; regularly hold lecture on emergency knowledge to improve emergency disposal ability when emergency disposal.

\subsection{Improvement of Supporting Measures}

In addition to the above several reference measures, it is also necessary to gradually improve various supporting measures of emergency management in the future for problems involved in cooperative mechanism for cross-regional emergency cooperation of many administrative regions, complicated event and member benefit, etc.; for example, the risk assessment mechanism, emergency rescue reimbursement system, cooperative mechanism supervision system and accountability system for dereliction of duty, etc. shall be established.

\section{Conclusion}

The paper summarizes and analyzes advanced experience of cooperative mechanism for cross-regional emergency management in America via comparison on cooperative mechanisms for cross-regional emergency management between China and America, and found that cooperative mechanism for cross-regional emergency management in America is much more flexible and effective; on the contrary, in China, the operating mechanism for cross-regional emergency management is still imperfect, for example, it is lack of legal framework of cooperation and permanent uniform command organization. So in the end of the paper it suggests that China should tighten up the legal system, optimize allocation of resources, raise emergency awareness amongst the general public. This paper can provide some helpful experience to improve China's cooperative mechanism for cross-regional emergency management.

\section{Acknowledgements}

The authors were supported by the National Natural Science Foundation of China (91646112), supported by Science and Technology Planning Project of Guangdong Province, China (2013B021500013), (2016A020224001).

\section{References}

[1] Tang, S.N. and Zhang, W. (2008) A Research on Cross-Regional Public Emergency 
Disposal System. Journal of China Three Gorges University (Humanities \& Social Sciences), 2, 27-30.

[2] Tang, X.Q. and Chen, G.H. (2011) Enlightenment from American Emergency Management Cooperation to Cross-Regional Emergency Management of China. Industrial Safety and Environmental Protection, 10, 51-53, 56.

[3] Office of Emergency Management (2014) An Investigation Report about Cross-Regional Emergency Management Cooperation Mechanisms. China Emergency Management, 3, 7-10.

[4] China State Council (2007) The Emergency Response Law of the People's Republic of China.

[5] The Emergency Management Assistance Compact (EMAC) Website. Who Administers EMAC? http://www.emacweb.org/?143

[6] Lv, Z.K. (2009) A Research on American EMAC: EMAC Males Cross-Regional Emergency Management works. Conference on Public Administration and Local Government Innovation, 120-162.

[7] Yang, L. and Zhen, C.Y. (2011) The Role of Regional Cooperation in Regional Public Crisis Management. Wuhan University Journal (Philosophy \& Social Science, 1, 57-68.

[8] Yang, L. and Dai, Y. (2009) The Role of Local Government Cooperation in Regional Cooperation. Journal of Northwest Normal University (Social Sciences, 5, 57-63.

[9] Zhang, W.X. (2011) E-Government Environment of the Emergency Management. Master Degree Thesis, Southwest Jiaotong University, Chengdu.

[10] Liu, Y.J. (2010) The Coping Strategies of Cross-Regional Crisis. Theoretical Exploration, 6, 119-121.

\section{Submit or recommend next manuscript to SCIRP and we will provide best} service for you:

Accepting pre-submission inquiries through Email, Facebook, LinkedIn, Twitter, etc. A wide selection of journals (inclusive of 9 subjects, more than 200 journals)

Providing 24-hour high-quality service

User-friendly online submission system

Fair and swift peer-review system

Efficient typesetting and proofreading procedure

Display of the result of downloads and visits, as well as the number of cited articles

Maximum dissemination of your research work

Submit your manuscript at: http://papersubmission.scirp.org/

Or contact jss@scirp.org 